\title{
Consumer Diversity In Multicultural Arenas: An Investigation Of Social Influences Between Asians And Westerners
}

Kritika Kongsompong, (Email: kritika.kongsompong@sasin.edu), Chulalongkorn University, Thailand

\begin{abstract}
The impact of people's orientation with regard to Collectivism/Individualism and to Locus of Control on the extent to which they are subject to social influence has never been investigated cross culturally in the context of consumer behavior in making purchasing decisions. The objective of this research is to compare the cultural orientations of people in the East and West, and to observe the effect of social influence in their decision making. In particular, this paper examines and adds evidence to the mutually exclusive cultures: Singapore, Thailand, Australia, and America. Hofstede's typology of cultures is reconfirmed and empirically associated with specific social influence variables on decision making. The findings provide either whole or partial supports for the hypotheses. In general, high collectivism is positively related with external locus of control and results in high level of social influence. There are exceptions, however, which highlight the need to incorporate other factors into understanding the role that cultural orientation plays in decision making.
\end{abstract}

\section{INTRODUCTION}

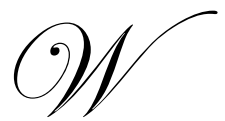

hat impact do cultural differences have on consumer behavior? This question has been the subject of much research and the answer has profound implications for marketers. Furthermore, in this era of globalization, part of the debate in management is whether regional markets should be considered as unique and requiring customized management tools and techniques, or to treat as though there are sufficient similarities across countries, thus applying a one-size-fit all strategy. The success of an organization in multicultural arenas may be largely affected by how well they are able to incorporate such understanding of cultural diversity into their management plans. Thus, one way that research scholars have attempted to address this managerial issue is through the study of cross-cultural differences in collectivism/individualism and its effects on various social-related constructs.

To date, many studies have been done on the marketing aspects of decision making issues. There is evidence of cultural differences in consumers across countries (Hiu, Siu, Wang \& Chang 2001; Kongsompong 2005), though no study has yet examined whether this effect extends to the social influence in decision making and applying it to global management. Thus, this paper aims to address such a gap in a cross-cultural study of social impact on decision making.

The choice of Singapore, Thailand, Australia, and America as the cultures for this study was made for three reasons; first, they are placed as extreme on the collectivist/individualist continuum according to Hofstede (1989, 2001). Second, these countries have a dominant cultures based on cultural heritage, Australia and America are AngloSaxon and Singapore and Thailand are Asian-Oriental. And third, they are significant trading partners in the global economy. Hence, the objective of this research is to compare the degree of collectivism/individualism of the people of these nations and attempt to associate them with various social influence in their decision making attempts.

This paper begins with a discussion of collectivism construct followed by a justification of the use of Hofstede's typology as a cultural framework. Then, rationale for using students as samples from Singapore, Thailand, 
Australia, and America, followed by the development of the hypotheses, method, and results. Finally, the academic and management implications are discussed.

\section{LITERATURE REVIEW}

\section{The Concept Of Culture}

One sense of culture, repeatedly referred to, implies cumulative development. Beliefs, behaviors, and/or artifacts are portrayed as developing through time, often toward some progressive, positive outcomes. One might cite Matthew Arnold (1950) in this regard: culture, he suggests, is "a pursuit of our total perfection. . the best which has been thought and said in the world". Culture, then, is what the people within the culture conceive it to be, and, as these definitions make clear, different people perceive it in different ways for different opinions. In sum, cultural concept emphasizes people's shared beliefs and behaviors that distinguish them from others and, at the same time, offer them a sense of shared meaning.

Cultural competency is an essential skill for global management since cultural diversity is increasing worldwide as immigration, travel, and the global economy make national borders more permeable. Thorough understanding and appreciation of culture will be more essential in day-to-day operations. To achieve this, cultural differences must be acknowledged, for instance, time perception and management differences among cultures. Some persons in many Asian cultures may have a relaxed sense of time, and personal relationships are considered more important than schedules. Thus, punctuality in the Western part of the world is highly crucial while their Asian counterparts may consider time punctuality as secondary to personal relationship.

The concept of culture can also be extended to cover various cultural constructs related to management. Cultural dimensions can help interpret business relationship building since they revolve around shared interaction and communication strategies across cultures. Hofstede (1991) has referred to Culture as "...the collective programming of the mind which distinguishes the members of one category of people from another." Specifically these cultural dimensions are seen as relevant to relationship building: power distance, individualism/collectivism (Hofstede, 1991), and high-context and low-context cultures (Hall, 1976). These dimensions will also be critical reviewed in the light of Hofstede's typology of culture.

\section{Hofstede's Typology Of Culture}

While the business world cannot avoid globalization, some executives have posed that homogenization of behavior is also occurring. However, there is little empirical evidence for this view at current. There seem to be a convergence of economic systems, but there is no evidence of convergence of peoples' value systems across cultures (de Mooij, 2000).

Hofstede's seminal typology of cultural dimensions was debuted in 1980 and continues to dominate in studies of management and marketing scholars. His work characterized culture with five dimensions: power distance or the degree of equality among people in society. Uncertainty avoidance is the dimension that reflects the degree to which people are able to tolerate ambiguity. The dimension of masculinity/ femininity determines the specific role of men vs. women in a society. Individualism/ collectivism concentrates on the degree to which people act as a group or as individuals, and long-term orientation or the degree to which people delay gratification of their material, social and emotional needs.

Although Hofstede's model has been widely used and challenged, many scholars agree that Hofstede's work has been insightful and useful in a number of ways. In the field of marketing, the cultural dimensions are helpful in understanding the characteristics of markets, which can be useful in making marketing decisions. To mention just a few, Hofstede's work helps international executives gain insights that can guide them in a range of activities, including market segmentation, selection of target market and market targeting, brand positioning, brand promotion and selection of promotional tools, conducting sales meetings, and cross-cultural negotiations. 


\section{Collectivism Construct}

The collectivism construct has long been established in business literature. Hofstede $(1991,2001)$ refers to individualism and collectivism as the basic beliefs that people hold with respect to their interaction with others and the world around them. Countries of the non-Western world are usually characterized as being collectivist in nature; whereas Westerners are often regarded as being individualists.

A defining feature of people who hold a collectivist orientation is that they either do not distinguish between personal and collective goals, or if they do, personal goals are subjugated to the goals of the collective (Triandis et al., 1990). Conversely, individualists are characterized by the tendency to give priority to individual goals over group goals. Since personal goals for individualist are obviously more important than group goals, the Westerner's motivation is usually treated by researchers as highly individualistic. Differences between the individualist and collectivist of pose intriguing questions among international management. Hence, the study of cross-cultural decision-making in regard to social influence will be highly beneficial for these managers in formulating specific competitive strategies.

\section{Locus Of Control Construct}

Rotter (1966) described the concept of "internal or external reinforcement of control", also called locus of control (LOC). Basically, an external control is when reinforcement is perceived by the subjects as following some action of his or her own but not being entirely contingent upon his/her action. It is typically perceived as the result of luck, chance, or fate; as under the control of powerful others, or as unpredictable because of the great complexity of the forces surrounding the individual. In contrast, an internal control reflects a person's perception that the event is contingent upon his/her own behavior or his/her own relatively permanent characteristics. Therefore, those with an internal versus external LOC hold different beliefs about the extent to which their actions can have an affect on the outcomes in their lives.

\section{Collectivism And Social Influence}

As cultural variables reflecting the values of people across cultures, individualism and collectivism can undoubtedly be identified as value orientations with respect to a person's or group's relationship to others. Specifically, collectivism and individualism have been identified as certain attitudes toward a person's or group's relationship (Hofstede, 1980; Triandis 1984, 1995). Researchers have reported significant differences between ingroup and out-group behaviors in collectivist cultures compared with individualist cultures (e.g., Godykunst et al., 1987; Leung \& Bond, 1984). Such results indicate that a person's self-definition as a member of a group determines how s/he behaves in social situations, such as relationship building, delegating, and communicating.

The importance of in-group acceptance as a group-related phenomenon lead to certain values being preeminent among collectivists, including security, good social and personalized relationships, and in-group harmony (Triandis et al., 1990; Schwartz, 1994). Collectivism is therefore expected to stress conformity and in-group harmony and defines the self in relation to the group (Triandis, 1995). Given the importance of group conformity and harmony among collectivists, one should expect that collectivist will be more responsive to group/social influence than will individualists.

\section{Locus Of Control And Social Influence}

Locus of control has proven itself to be highly useful in distinguishing the active/passive attitudes of individuals in relation to their environment. Moreover, differences in locus of control may explain why people differ in the ways they respond to successful or unsuccessful experiences. According to Lefcourt (1982), the trends in theory and research pertaining to locus of control will continue to differentiate the behavior of external and internals as follows: 
- $\quad$ Contrary to externals, internals are associated with purposeful decision making and confidence in the ability to succeed at a valued task,

- Opposite from an external LOC orientation, internals has been found to be associated with more active attention to information pertinent to outcomes, and

- Internals are more resistant to social influence while externals are more attentive and yielding to social cues.

\section{HYPOTHESES}

Based on the preceding literature, four hypotheses related to collectivism and social influence were developed for testing in a decision making situation. The first hypothesis pertains to social influence toward collectivists and individualists. This hypothesis is based upon the literature discussed above which suggests that collectivists are relatively more susceptible to social influence than their counterpart.

H1: Overall, collectivists are more socially influenced than individualists.

The tests of $\mathrm{H} 1$ will combine subjects from the four selected countries (Thailand, Singapore, Australia, and America), regardless of their label as individualist or collectivist. The opinion of significant others such as parent/authority figure, friend, and boy/friend are included to determine if people who exhibit relatively collectivist orientation are subject to higher levels of influence than are those who are relatively individualist in their orientations.

The second hypothesis is confirmatory in nature, since it seeks to confirm relative collectivism/individualism levels that had been established by Hofstede (1991, 2001). Recently, Hofstede (2001) undertook research on 72 countries that demonstrates cultural differences on the basis of his five dimensions. This particular study, however, shall investigate solely the collectivist dimension to determine its relationship to social influence. The confirmation is believed to be necessary because this study employs a different scale by which to measure collectivism.

H2: Asians are relatively more collectivist than Westerners.

According to Rotter (1966), internals are people who believe that they are in control of their own destiny, while externals are those who believe that what happens to them is the result of uncontrollable factors-such as fate, chance, or significant others. H3 attempts to relate locus of control construct with the collectivist construct of Hofstede's cultural dimensions.

When examining cultural differences in locus of control, findings repeatedly suggest that members of independent cultures judge the individual to be the responsible agent of actions (internals), while members of interdependent cultures judge situations or social groups to be the directors of actions (externals) (Holland et. al 1986; Morris and Pend 1994). In this hypothesis, therefore, Thais and Singaporeans (collectivists) should be more external in locus of control than Australians and Americans (individualists)

H3: Asians exhibit more external orientation in locus of control than Westerners.

According to Hofstede's cultural dimension (2001), both Thailand and Singapore were reported to exhibit low scores on the 'individualism' dimension. On the opposite side, Australia and America were reported as high on the same dimension. If this hypothesis is accepted, one can reconfirm that Thais and Singaporeans are more collectivist than Australians and Americans.

The fourth hypothesis recaps the overall findings and attempts to investigate on the level of social influences toward the subjects in each country. From the literature, people in the Asian cultures are more likely to perceive group collectives as the determinants of their behavior. Therefore, Asians (Thais and Singaporeans) should exhibit greater social influence in their decision endeavors than their Western counterparts (Australians and Americans).

H4: Asians are more socially influenced in their decision making than Westerners. 


\section{METHODOLOGY}

\section{Data Collection}

Four sets of questionnaires were distributed to respondents in four countries: Thailand, Singapore, Australia, and America. The questionnaires were administered in classroom settings. Respondents were undergraduate business students at major state universities in each of the four countries as it allowed control for extraneous factors. Furthermore, in just a few years, these students will enter the workforce. Thus, prudent executives should incorporate this new knowledge into their perspective business strategies.

The mean age for all countries was 20.3 and the total sample size was 797. After elimination of respondents with missing data, the final sample size comprised: Thailand $(n=243)$, Singapore $(n=124)$, Australia $(n=205)$, and America $(\mathrm{n}=198)$. While data was collected from four countries, the unit of analysis here is the individual. According to Darwar and Parker (1994), studies based on an individual's cultural orientation, rather than nationality, provides greater explanatory power because it enables us to attribute differences to cultural norms and traits, and to extrapolate beyond the countries included in any sample. This focus is necessary since, cultural values need to be measured and operationalized at the individual level, otherwise nation-level culture may lead to false stereotyping.

Since this study involves cross-cultural research, the comparability of the sample is an important issue. Noncomparable samples could lead to alternative explanations for any observed differences across the samples (Brislin, Lonner, and Thorndike, 1973). Sample comparability was addressed in this study by using respondents in the same age group and occupational status - undergraduate business students. Furthermore, statistical comparison was made between samples based on a demographics test in age, sex, family income, and parent's level of education. No significant differences were found.

According to Malholtra et al. (1996) and Wharton et al. (1991), back translation requires that the questionnaire is translated from the base language by a bilingual speaker whose native language is the language into which the questionnaire is being translated. This version is then translated back into the original language by a bilingual whose native language is the initial or base language. Since not all Thai people are proficient in the English language, this method of "back translation" was implemented.

\section{Scales}

To capture the collectivist and individualist nature of all subjects in the study, a seven-point $(7=$ Strongly agree, $\ldots . .1$ = Strongly disagree), 10 -item collectivism scale developed by Yamaguchi (1990c) was employed. The scale describes behavioral choices that favor group goals in situations where group and personal goals come into conflict. Other characteristics and tendencies (i.e. expectation of reward or punishment in the presence of others) that have been found to differentiate between collectivists and individualists are also included in this scale.

According to Busseri et al. (1996), a five-point ( 5 = Strongly agree, $\ldots 1=$ Strongly disagree), 14-item consumer-focused LOC scale should be a useful measure of consumer beliefs that can provide some prediction of differences in the ways that people approach the task of shopping. Internals are those who see themselves as effective shoppers while externals cannot.

The social influence scenario and scale of Lee and Green (1991) was used to capture the dependent variable in this study. This scale represents the degree of social influence that three significant others have on decision making (parent/authority figure, friend, and boy/girlfriend). A shopping scenario was integrated into the study since all subjects would have first hand experience with shopping.

You need to buy some new sneakers. You are considering two models, one that you like, and another that is liked by the person who is with you. How likely would you be to purchase the sneakers that the other person likes if that person is your parent/boss (friend, boy/girlfriend)? 
A 7 point, single item, rating scale was employed to capture social influence with endpoints ranging from 'very likely' to 'very unlikely'. Being sourced from extant literature, the scales were considered to have construct validity. Face validity was achieved by pre-testing the questionnaires to a convenience sample of undergraduate students in each country.

The measurement scale in this study was examined for its internal consistency by investigating the inter-item correlation matrix and a number of reliability coefficient (Churchill 1979; Nunnally and Bernstein 1994; Robinson et al. 1991). Rule of thumb for corrected item-to-total correlations is that they should be 0.50 or greater (Bearden et al. 1989; Shimp and Sharma 1987). Basic guideline for individual correlations in the inter-item correlation matrix may vary. Robinson and colleagues (1991) recommend the level of 0.30 or better. The most widely used internal reliability coefficient is cronbach's (1951) coefficient alpha. The acceptance level can go as low as 0.70 or 0.60 (Robinson et al. 1991). All of the measures used in this study have Crobach's alpha above 0.60 indicating acceptable reliability.

\section{ANALYSIS AND RESULTS}

H1 tests whether collectivists are more socially influenced than individualists. To achieve insights for this hypothesis, the variable 'collectivist total' is run from the pooled data for all of the four countries. Respondents from the combination set are separated into two groups, collectivists and individualist, based on the application of subgroup analysis (Kohli, 1989). The findings indicate that the collectivists $(n=425)$ have a social influence mean of 4.02 (standard deviation $=1.74)$, while the individualist $(\mathrm{n}=344)$ have a social influence mean of 3.45 (standard deviation $=1.74)$.

ANOVA is employed to determine whether the collectivist group exhibits significantly higher levels of social influence than the individualist group. The significant of F-value indicates whether the collectivists are significantly different from the individualists. Table 1 shows ANOVA results for the evaluation of the differences between collectivists and individualists in regard to the sum all of the social influences. The results clearly indicate that collectivists are more susceptible to social influence than individualists.

Table 1: Social Influence: The Differences Between Collectivists And Individualists

\begin{tabular}{|c|c|c|c|c|c|}
\hline Social Influence & $\begin{array}{c}\text { Individualist } \\
\text { Mean (S.D.) }\end{array}$ & $\begin{array}{c}\text { Collectivist } \\
\text { Mean (S.D.) }\end{array}$ & F-Value & Df. & Sig. \\
\hline Parents/Authority & $3.61(1.76)$ & $3.97(1.75)$ & 7.78 & 737 & .01 \\
\hline Friends & $4.32(1.48)$ & $4.81(1.48)$ & 23.11 & 737 & .00 \\
\hline B/Girlfriend & $4.76(1.55)$ & $5.12(1.37)$ & 11.20 & 737 & .00 \\
\hline All Influences & $4.23(1.60)$ & $4.63(1.53)$ & 23.01 & 737 & .00 \\
\hline
\end{tabular}

$\mathrm{H} 2$ is a replication hypothesis - i.e., that Asians (Thais and Singaporeans) are typically more collectivist than the Westerners (Australians and Americans). MANOVA is employed here to investigate the differences. The dependent variables for this part of the study are the components from factor analysis and the 'collectivist total' construct. The univariate tests reveal that each component of collectivist constructs has unique differences across the countries. Specifically, 'harmony', 'peer support', 'conflict avoidance', and collectivist total' are reported to have significance level $<0.00$. Scheffe test is then employed to determine the significance of the differences that exist between each pair of countries.

Group profile and Scheffe tests are conducted to determine if the exhibited differences exist in correspondence with the hypothesis. The Scheffe test enables us to make all possible comparisons between the individual countries while controlling overall Type I error (Hair et al., 1998). The data in Table 3 supports this assertion: Thais and Singaporeans have mean collectivism scores of 5.06 and 4.98, respectively; versus 4.72 and 4.68 for Australians and Americans, respectively. 
Table 2: Country Comparison On Collectivism Scale

\begin{tabular}{|c|c|c|c|}
\hline Country & & Mean Difference & Sig. $(\mathbf{p}<)$ \\
\hline Thailand & Singapore & 0.08 & .81 \\
(Mean: 5.06; Std dev 0.52) & Australia & 0.33 & .00 \\
& U.S.A. & 0.38 & .00 \\
\hline Singapore & Thailand & -0.08 & .01 \\
(Mean: 4.98; Std dev 0.66) & Australia & 0.26 & .00 \\
\hline Australia & U.S.A. & 0.31 & .00 \\
(Mean: 4.72; Std dev 0.66) & Thailand & -0.33 & .01 \\
\hline U.S.A. & Singapore & -0.26 & .94 \\
(Mean: 4.68; Std dev 0.62) & U.S.A. & 0.04 & .00 \\
& Thailand & -0.38 & .94 \\
\hline
\end{tabular}

Note: Differences assessed using a multiple range (Scheffe) test of significance.

$\mathrm{H} 3$ predicts that Asians exhibit more external orientation in locus of control than Westerners. ANOVA is employed to investigate the differences between Thai/Singaporean subjects and Australian/American subjects. The dependent variable for this part of the study is the means of locus of control, while the independent variables are the countries being investigated. Table 3 shows that Thailand $($ Mean $=2.77)$ reports to be the most external, Singapore $($ mean $=2.63)$ the second most external, Australia $($ Mean $=2.49)$ the third, and U.S.A. $($ mean $=2.34)$ the least.

Table 3: Mean Comparison For Locus Of Control

\begin{tabular}{|c|c|}
\hline Country & LOC Mean (Std. Dev.) \\
\hline Thailand & $2.77(0.42)$ \\
\hline Singapore & $2.63(0.44)$ \\
\hline Combined: East/Asians & $2.72^{\mathrm{a}}(0.43)$ \\
\hline Australia & $2.49(0.48)$ \\
\hline U.S.A. & $2.34(0.51)$ \\
\hline Combined: West/Non & $2.41^{\mathrm{b}}(0.50)$ \\
\hline
\end{tabular}

Note: Using ANOVA, means for ' $a$ ' are significantly different from ' $b$ '.

H4 states that Asians are more socially influenced in their decision making than Westerners. MANOVA is employed here to investigate the differences between Thai/Singaporean subjects and Australian/American subjects. The dependent variables for this part of the study are the reported levels of social influence respondents have upon their parent/authority figure, friend, and boy/girlfriend. The independent variables are each of the countries: Thailand, Singapore, Australia, and America. The univariate test reveals that these dependent variables have unique differences across the countries. Specifically, parent/authority figure, friend, and boy/girlfriend reported a significance level of 0.00 .

The Scheffe tests are also conducted to determine if the diagnosed differences exist for each of the four countries on the social influence issue. Table 4 shows the Scheffe summary on the differences between the countries being studied and social influence level. The directionality of the findings is consistent with the hypothesis, since Asians (Thailand and Singapore) report higher levels of influence than Westerners (Australia and America), although the difference between Singapore and Australia is not statistically significant.

\section{DISCUSSION}

The hypotheses stated in this study are concerned with the extent to which people from the four countries are subject to social influences based on whether they are classified as individualists or collectivist, Asians or Westerners. The Thais and Singaporeans are consistently found to be more collectivist than the Australians and Americans. All of the collectivist components - 'harmony', 'peer support', 'conflict avoidance', and 'collectivist total' - consistently 
demonstrate higher means for the Thais and Singaporeans than their Australian and American counterparts. Moreover, on most factors, there is a hierarchy relating to the level of collectivism/individualism: Thailand is the most collectivist followed by Singapore. America is the most individualist, followed by Australia.

Table 4: Country Comparison On Social Influence

\begin{tabular}{|c|c|c|c|}
\hline Country & & Mean Difference & Sig. $(\mathbf{p}<)$ \\
\hline Thailand & Singapore & 0.39 & .02 \\
(Mean: 4.57; Std dev 1.04) & Australia & 0.52 & .00 \\
& U.S.A. & 1.01 & .00 \\
\hline Singapore & Thailand & -0.39 & .02 \\
(Mean: 4.18; Std dev 1.13) & Australia & 0.13 &. $\mathbf{7 8}^{*}$ \\
\hline Australia & U.S.A. & 0.62 & .00 \\
(Mean: 4.05; Std dev 1.07) & Thailand & -0.52 & .00 \\
& Singapore & -0.13 & .00 \\
(Mean: 3.56; Std dev 1.20) & U.S.A. & 0.49 & .00 \\
& Thailand & -1.01 & .00 \\
\hline
\end{tabular}

Note: Differences assessed using a multiple range (Scheffe) test of significance.

The data pertaining to $\mathrm{H} 3$ shows as an acceptance to the prediction that Thailand and Singapore are significantly more external in their LOC orientation than both Australia and U.S.A. The finding is expected and is congruent with research literature (Holland et al. 1986) that collectivists are more likely to have external locus of control than individualists.

The findings, however, indicate mixed evidence for the application of collectivism construct on the social influence among Singapore and Australia. It appears from the results that while a culture may be classified according to Hofstede's cultural dimension, they do not all interact consistently with each other. Since the Australians are high on individualism, one would expect they would be less concerned about other people when making decisions. They should be more self-focused than the Singaporeans who are more collectivist and more concerned about opinions of others. The results from this study imply that other factors may be involved in the level of social influence experienced in decision making situations in additional to individualism/collectivism.

Over time, nations and cultures change (Hoyer and MacInnis 1997), and some changes may be associated with changes in behavioral patterns. As the economic status of the country has changed, for instance, it is also possible that certain aspects of the culture and related behaviors of the people have also changed. Although Singapore shows greater individualist than that of Thailand, Singapore is still relatively collectivist culture when compared to Australia and America. The economic factor, however, appears to be closely associated with the social influence findings. Table 5 shows that Thailand consistently has the lowest per capita GDP of the four countries, and concurrently reports the highest level of social influence. At the other end of the spectrum, America has the highest per capita GDP, and reports the lowest levels of social influence. Singapore and Australia, however, exhibit the same level of GDP, particularly in recent years. They also exhibit similar levels of social influence in decision makings. This evidence is strictly correlational and its actual validity would need to be the subject of future research.

Table 5: World Per Capita Gross Domestic Product Using Market Exchange Rates (Thousands Of 2000 U.S. Dollars)

\begin{tabular}{|c|c|c|c|c|c|c|}
\hline & $\mathbf{1 9 8 0}$ & $\mathbf{1 9 8 5}$ & $\mathbf{1 9 9 0}$ & $\mathbf{1 9 9 5}$ & $\mathbf{2 0 0 0}$ & $\mathbf{2 0 0 3}$ \\
\hline Thailand & 0.8 & 0.9 & 1.5 & 2.1 & 2.0 & 2.2 \\
\hline Singapore & 9.2 & 12.1 & 14.6 & 19.5 & 23.0 & 22.1 \\
\hline Australia & 12.7 & 13.8 & 15.1 & 17.1 & 19.8 & 21.0 \\
\hline America & 22.8 & 25.4 & 28.5 & 30.6 & 34.8 & 35.7 \\
\hline
\end{tabular}

Source: Organization for Economic Co-Operation \& Development 1980-2003 


\section{LIMITATIONS}

A major limitation of the study concerns the nature of the sample, which comprised college students. University students were used for the sampling mainly because of the comparison nature of the study. They represent closely matched samples that enable rigorous cross-national comparison. The limitation exists, however, because student samples are not necessarily representative of the overall population. The external validity of the findings, therefore, is compromised.

Another limitation relates to the results that derived from only four countries rather than from a large number of countries. These four countries are used because of consistent identification as collectivists and individualists in previous research. However, this sample of nations does not necessarily reflect the findings of sample from other nations. Thus, the presentation of the results and the implications should be interpreted in the context of this limitation.

\section{MANAGEMENT IMPLICATIONS}

This study has shown specific cross-cultural differences in decision making endeavors. In particular, level of social influence is integrated with Hofstede's typology of culture and the framework concentrated on the collectivism construct is empirically tested.

There are a number of managerial implications emerging from the research. First, the theoretical analysis provides insight on how cultural background is affected by social influence on decision making. Second the research indicates that managers and practitioners need to consider cultural background in recruiting, selecting, and training workforce on day-to-day, as well as strategic operations. As noted by Hoppe (2004), the study of cultural values and beliefs is essential to effective globalization and management strategy as it enables the improvement of managerial processes.

Third, multinational enterprises need to be careful about generalizations and stereotyping on the basis of Hofstede's typology. While Singapore and Australia reflected traditional Asian and Western typologies, the collectivist dimension does not always have the expected results in level of social influence.

In conclusion, as we can't avoid globalization, it is imperative that global executives learn as much as they can about the differences in workforce and customers cross-culturally. The success of a multinational enterprise may be largely affected by how well management can incorporate such diversities into their management strategies. With this reason, sustainable competitive advantage belongs to those who are continuously enhanced with knowledge, and able to adapt these new insights into their strategic plans.

\section{REFERENCES}

1. $\quad$ Arnold, M. (1960-77) The Complete Prose Works of Matthew Arnold (11 Vols., Ed. R.H. Super). Ann Arbor: University of Michigan Press.

2. Brislin, Lonner, and Thorndike (1973) Cross-Cultural Research Methods, New York: Wiley.

3. Darwar, N. and Parker, P. (1994) Marketing Universals: Consumers use of brand name, price, physical appearance, and retail reputation as signals of product quality, Journal of Marketing, 58, April, pp 81-95.

4. De Mooij, M. (2000) The future is predictable for international marketers: Converging incomes lead to diverging consumer behavior, International Marketing Review, 17(2), pp 103-113.

5. Godykunst, W.B., Yoon, Y., and Nishida, S. (1987) The influence of individualism-collectivism on perceptions of communication in in-group and out-group relationship, Communication Monographs, 54, pp 295-306.

6. Hair, J. F., Jr., Anderson, R., Tathom, R. L., and Black, W. C. (1995) Multivariate data analysis with readings, $4^{\text {th }}$ ed. Englewood Cliffs, New Jersey: Prentice Hall.

7. Hall, E. T. (1976) Beyond Culture. Garden City, NY: Doubleday. 
8. Hiu, A. S. Y., Siu, N. Y. M., Wang, C. C. L., \& Chang, L. M. K. (2001) An investigation of decision-making styles of consumers in China, The Journal of Consumer Affairs, 35(2), pp 326-346.

9. Hofstede, G. H. (1991) Cultures and Organizations: Software of the Mind NY: McGraw-Hill.

10. Hofstede, G. (2001) Culture's Consequences: Comparing Values Behaviors, Institutions, and Organization across Nations, London: Sage Publications.

11. Holland, J. H., Holyoak, K. J., Nisbett, R., and Thagard, P. R. (1986). Induction: Processes of inference, learning, and discovery. Massachusetts: MIT Press.

12. Hoppe, M. H. (2004) Introduction: Geert Hofstede's culture's consequences: International difference in work-related values, Academy of Management Executive, 18(1), pp 73-74.

13. Hoyer, W. D. and MacInnis, D. J. (1997) Consumer Behavior, Boston: Houghton Miffin.

14. Kohli, A. J. (1989) Determinants of influence in organizational buying: A contingency approach, Journal of Marketing, 53 (July), pp 50-65.

15. Kongsompong, K. (2004) Sex, social influence, and locus of control: A multicultural analysis on consumer behavior, Sasin Journal of Management, Volume 10 (1).

16. Lee, C. and Green, R. T. (1991) Cross-cultural examination of the Fishbein's behavioral intentions models, Journal of International Business Studies, 22(2).

17. Malholtra, N. K., Agarwal, J. M., and Peterson, M. (1996) Cross-cultural marketing research: Methodological issues and guidelines, International Marketing Review, 13(5), pp 7-43.

18. Organization for Economic Co-Operation \& Development (1980-2003), World Per Capita Gross Domestic Product Using Market Exchange Rates.

19. Robinson, J. P., Shaver, P. R., and Wrightsman, L. S. (1991) Criteria for scale selection and evaluation. In J. P. Robinson, P. R. Shanver, and L. S. Wrightsman (Eds.), Measures of personality and social psychology, 61, pp 755-765.

20. Triandis, H. C. (1995) Individualism and Collectivism, Boulder, Colorado: Westview Press.

21. Triandis, H. C., Bontempo, R., Leung, K., and Hui, C. H. (1990) A method of determining cultural, demographick and personal constructs, Journal of Cross-Cultural Psychology, 21, pp 302-318.

22. Schwartz, S. H. (1994) Beyond Individualism and Collectivism: New Cultural Dimensions of Values, In U. Kim, H. C. Triandis, C. Kagitcibasi, S. C. Choi, and G. Yoon (Eds.), Individualism and Collectivism: Theory, Method, and Applications (pp. 85-112). Newbury Park, California: Sage.

23. Wharton, R., Baird, I. S., and Lyles, M. A. (1991). Conceptual frameworks among Chinese managers: Joint venture management and philosophy, Journal of Global Marketing, 5(1-2), pp 163-181.

24. Yamaguchi, S. (1994) Empirical evidence on collectivism among the Japanese, In U. Kim, H. C. Triandis, C. Kagitcibasi, S. C. Choi, and G. Yoon (Eds.), Individualism and Collectivism: Theory, Method, and Applications (pp. 175-188). Newbury Park, California: Sage. 